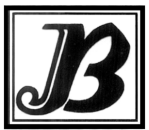

J. Bio-Sci. 29(2): 53-60, 2021 (December)

ISSN 1023-8654 http://www.banglajol.info/index.php/JBS/index DOI: https://doi.org/10.3329/jbs.v29i2.54954

\title{
MORPHOMETRIC AND MERISTIC CHARACTERISTICS OF WALKING SNAKEHEAD CHANNA ORIENTALIS IN A WETLAND ECOSYSTEM (NORTHWESTERN BANGLADESH) USING MULTI-LINEAR DIMENSIONS
}

\author{
AA Chowdhury ${ }^{1}$, MY Hossain ${ }^{1}$, FA Rima ${ }^{1}$, M Ashekur Rahman ${ }^{1}$, Z Mawa', MA Islam 1 , M Ataur \\ Rahman ${ }^{1}$, MR Hasan ${ }^{1}$, S Tanjin ${ }^{1}$, MS Sarmin ${ }^{1}$, O Rahman ${ }^{1}$ and MA Samad ${ }^{1,2}$ \\ ${ }^{1}$ Department of Fisheries, Faculty of Agriculture, University of Rajshahi, Rajshahi-6205, Bangladesh \\ 2Department of Fisheries and Marine Bioscience, Jashore University of Science and Technology, Jashore \\ 7408, Bangladesh
}

\begin{abstract}
The present study is illustrated complete morphometric and meristic characteristics of fresh water fish, walking snakehead, Channa orientalis (Bloch \& Schneider 1801), using nine linear dimensions and covering different fin-rays (i.e., dorsal fin, $\mathrm{D}$; pectoral fin, $\mathrm{P}_{1}$; pelvic fin, $\mathrm{P}_{2}$; anal fin, $\mathrm{A}$ and caudal fin, $\mathrm{C}$ ) from the wetland ecosystem Gajnar Beel in northwestern (NW) Bangladesh. Total 230 specimens of $C$. orientalis were collected from the Gajnar Beel in the time of January to December 2018 by several local fishing gears (e.g., cast net, gill net and square lift net (mesh size ranges: $1.5-2.5 \mathrm{~cm}, 1.5-2.0 \mathrm{~cm}$, \& $\sim 2.0 \mathrm{~cm}$, respectively). Different morphometric lengths were measured to $0.01 \mathrm{~cm}$, and whole body weight (BW) was estimated $0.01 \mathrm{~g}$ for each individual. Fin rays and scales (including lateral line scale) were computed by a magnifying glass. All LWRs were highly significant $(p<0.0001)$ with the $r^{2}$ values $\geq 0.978$. Based on $r^{2}$ value, LWR by BW vs. TL was the best fitted model among nine equations. However, the LLRs were also significant with $r^{2}$ values $\geq 0.992$. According to $r^{2}$ value, LLR by TL vs. SL $(T L=a+b \times S L)$ shown the best fitted model among eight equations. The fin formula of $C$. orientalis is: dorsal: D. 29-35; Pectoral, P1. 12-14; Pelvic, P2. 5-6; Anal, A. 20-22; Caudal, C. 12-14. A double lateral line is present which continued with $12-13$ scales in the first line and 26-28 scales in other line. The present study will be helpful for the species identification and resource management of $C$. orientalis in the Gajner Beel NW Bangladesh and other sub-tropical countries.
\end{abstract}

Key words: Channa orientalis, Gajner Beel, Length-weight relationship, Length-length relationship, Meristic

\section{Introduction}

The walking snakehead, Channa orientalis (Bloch and Schneider 1801) is a freshwater widely adapted species belonging to the family of Channidae under the order of Perciformes (Rahman 1989). It is known as Cheng or ghachua in Bangladesh; Chengal, Cheng in India; Nga-yan-goungdo, in Myanmar; Brown snakehead, Smooth-breasted snakehead in Sri Lanka, Chenga, Garahi in Nepal. C. orientalis is well-known in Indian subcontinent and surrounding areas ranging across Afghanistan, Bangladesh, India, Myanmar, Nepal, Pakistan and Sri Lanka. This species is an economically essential target and most favored aquarium fish species through Asian countries (Froese and Pauly 2019). C. orientalis is piscivorous, carnivorous species and easily attracted by any moving baits (Rahman 1989). C. orientalis are found in freshwater environment including rivers, lakes, ponds, mountain streams and even brackish water (Rainboth 1996). This

*Author for correspondence: hossainyeamin@gmail.com, yeamin.fish@ru.ac.bd 
species has a high market price and also has huge survival in adverse situation. This species is vulnerable through worldwide (IUCN 2019) and as of least concern in Bangladesh (IUCN 2015).

The term 'morphometric' can be defined as a technique for describing body form by measuring the length or distance between physical features or landmarks (Muchlisin 2013). On the other hand, meristic is an area of ichthyology which relates to counting quantitative feature of fish, such as the number of fins or scales. Morphometric and meristic counts are very useful for the species identification, sex determination and classification of any fish species in a laboratory or in the fields (Bagenal and Tesch 1978, Dynes et al. 1999, Jayaram 1999, Nawer et al. 2017, Rahman et al. 2019). So, studies on morphometric and meristic features can be constructive tools for exact identification of any species and its classification (Bagenal and Tesch 1978, Hossen et al. 2016, Islam et al. 2020). Moreover, in fisheries research, appraising the well-being of individuals as well as evaluating the life history and the morphological traits of populations of different locality greatly relies on morphometric characters (King 2007, Hossain 2010, Hossain et al. 2013, Hasan et al. 2020). There are very few works have been done on length-weight relationships and morphometric and meristic variation in fins of $C$. orientalis (Charjan and Kulkarni 2014, Sharma et al. 2015, Hossain et al. 2017a). However, no profound studies have been conducted on this species yet from the Gajner Beel and elsewhere. Details and perfect information on morphometric and meristic characters of $C$. orientalis is really needed for the proper management. So, this study will provide the first complete and informative description on morphometric characters, length-weight relationships (LWRs), length-length relationships (LLRs) and meristic characters of $C$. orientalis from the Gajner Beel in NW Bangladesh using multi-linear dimensions.

\section{Material and Methods}

\section{Fish sampling}

This study was continued in Gajner Beel, northwestern Bangladesh (23⒌' N; $\left.89^{\circ} 52^{\prime} \mathrm{E}\right)$ from January to December 2018. A total of 230 individuals of $C$. orientalis were collected through various types of traditional fishing gears including Cast net, Gill net and Square lift net (mesh size ranges: $1.5-2.5 \mathrm{~cm}, 1.5-2.0 \mathrm{~cm}$, \& $\sim 2.0 \mathrm{~cm}$, respectively). At sampling site samples were chilled by ice in the ice box and after reaching in the laboratory samples were preserved with $10 \%$ buffered formalin.

\section{Fish measurements}

Digital electronic balance was used for taking individual body weight near to the $0.01 \mathrm{~g}$, accuracy. Different linear dimensions (i.e., total length (TL) ; standard length ( $\mathrm{SL}$ ) ; pre-dorsal length (PrDL) ; post-dorsal length (PoDL) ; anal length, (AnL); pre anal length (PrAnL); post anal length (PoAnL) (Fig. 1)were measured by measuring board near to the $0.1 \mathrm{~cm}$ accuracy.

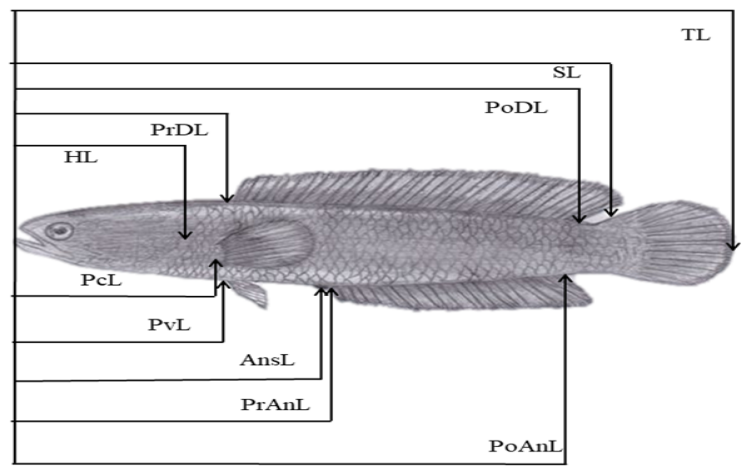

Fig. 1: Showing the morphometric measurement of Channa orientalis from Gajner Beel, NW Bangladesh. 


\section{Meristic counts}

The meristic counts of fin rays of $C$. orientalis in various body parts like dorsal, pectoral, pelvic and caudal fins was detected by a magnifying glass with zoom range $4 x$.

\section{Growth pattern}

The relationships of morphometric between body weight and lengths were calculated as $W=a \times L^{b}$, where ' $W$ means the body weight $(\mathrm{g}$ ) and ' $\mathrm{L}$ ' means the various lengths (e.g., Total length, TL; standard length, SL etc.) in $\mathrm{cm}$. $a$ and $b$ known as regression parameters, calculated through linear regression analyses which depends on natural logarithms: $\ln (W)=\ln (a)+b \ln (L)$. Here, $95 \%$ confidence limit $(C L)$ of $a$ and $b$ and the co-efficient of determination $\left(r^{2}\right)$ were also calculated from this way of analyses. In this study, analysis of LLRs was done by linear regression analysis. The best model for both LWRs and LLRs was determined by the highest $r^{2}$ value.

\section{Statistical analyses}

GraphPad Prism 6.5 software was used for statistical analyses of correlation with the consideration of $5 \%$ $(p<0.05)$ significant level.

\section{Results}

The body shape of $C$. orientalis is elongated, fairly rounded in cross-section. Mouth is large with villi form teeth on jaws. Eyes are moderate, its diameter 5 to 6 times in head length. Pectoral fin is extending to anal fin and pelvic fin about $50 \%$ of pectoral fin length. Caudal fin is rounded. Large plate-like scale is on head. Body colour is black to light green on dorsal side and white to pale on ventral side with a faint bluish or reddish tinge. Pectoral fin with a series of distinct alternating blue and pale orange vertical bands; outer margins of the dorsal, caudal and anal fins are slate-coloured with scarlet and barred strips (Fig. 2).

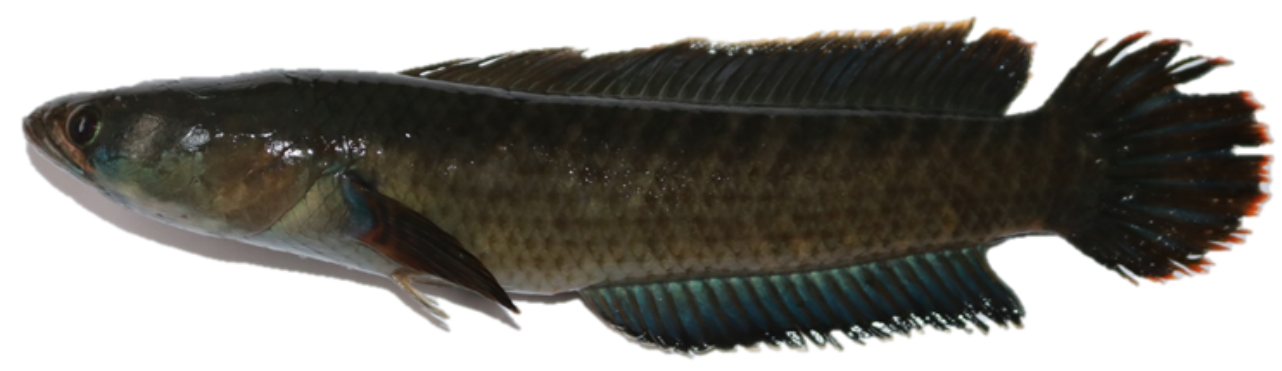

Fig. 2: Photo of Channa orientalis which was captured from Gajner Beel, NW Bangladesh.

In this study, $\mathrm{TL}$ was varied from $7.9-18.5 \mathrm{~cm}(\mathrm{Mean} \pm \mathrm{SD}=13.82 \pm 2.47)$ and $\mathrm{BW}$ was diverse from 4.61$70.72 \mathrm{~g}$ (32.03 \pm 16.42$)$ (Table 1). Regression parameters $a$ and $b$ with $95 \%$ confidence intervals and coefficients of determination $\left(r^{2}\right)$ for LWRs of $C$. orientalis are shown in Table 2. All LWRs were highly significant $(p<0.0001)$ with $r^{2}$ values $\geq 0.978$. Based on $r^{2}$ value, LWRs by BW vs. TL was the best fitted model among nine equations. The LLRs are shown in Table 3 and all relationships were also highly correlated $(p<0.0001)$ with $r^{2}$ values $\geq 0.992$. On the basis of maximum $r^{2}$ value, LLRs by TL vs. SL was the best fitted model among eight equations. 
Table 1. Morphometric measurements of the Channa orientalis captured from the Gajner Beel, NW Bangladesh

\begin{tabular}{lccccc}
\hline Measurements & Min. (cm) & Max. (cm) & Mode (cm) & Mean \pm SD & $\%$ TL \\
\hline TL (Total length) & 7.9 & 18.5 & 16.5 & $13.82 \pm 2.47$ & - \\
SL (Standard length) & 6.3 & 15.3 & 12.3 & $11.38 \pm 2.10$ & 82.70 \\
PrDL (Pre-dorsal length) & 2.1 & 5 & 3.5 & $3.74 \pm 0.66$ & 27.02 \\
PoDL (Post-dorsal length) & 5.7 & 14.2 & 9.8 & $10.66 \pm 1.95$ & 76.75 \\
PcL (Pectoral length) & 2 & 4.8 & 3.5 & $3.57 \pm 0.62$ & 25.94 \\
PvL (Pelvic length) & 2.4 & 5.8 & 4.1 & $4.18 \pm 0.75$ & 31.35 \\
AnsL (Anal length) & 3.2 & 7.8 & 6.6 & $5.99 \pm 1.11$ & 42.16 \\
PrAnL (Pre-anal length) & 3.1 & 8.1 & 6.1 & $6.10 \pm 1.11$ & 43.78 \\
PoAnL (Post-anal length) & 5.5 & 13.7 & 9.6 & $10.27 \pm 1.83$ & 74.05 \\
BW (Body weight) & 4.61 & 70.72 & 26.02 & $32.03 \pm 16.42$ & - \\
\hline
\end{tabular}

Min. $=$ Minimum, Max. $=$ Maximum, $S D=$ Standard deviation, ${ }^{*}$, weight in gram.

Furthermore, the fin formula presents only soft fin rays and their number varies. In our study, the fin formula was D. 29-35; P1. 12-14; P2.5-6; A. 20-22; C. 12-14 (Fig. 3). A double lateral line is present which continued with 12-13 scales in the first line and 26-28 scales in other line.

Table 2. Descriptive statistics and estimated parameters of the length-weight relationships of Channa orientalis $(n=230)$ captured from the Gajner Beel, NW Bangladesh

\begin{tabular}{|c|c|c|c|c|c|}
\hline \multirow{2}{*}{ Equation } & \multicolumn{2}{|c|}{ Regression parameter } & \multirow{2}{*}{$95 \% \mathrm{CL}$ of $\mathrm{a}$} & \multirow{2}{*}{$95 \% C L$ of $b$} & \multirow{2}{*}{$r^{2}$} \\
\hline & a & $b$ & & & \\
\hline$B W=a^{\star} T L^{b}$ & 0.0069 & 3.17 & 0.0059 to 0.0082 & 3.117 to 3.234 & 0.978 \\
\hline$B W=a^{*} S L^{b}$ & 0.0171 & 3.05 & 0.0147 to 0.0200 & 2.990 to 3.119 & 0.974 \\
\hline$B W=a^{*} \operatorname{Pr} D L^{b}$ & 0.4383 & 3.16 & 0.3715 to 0.5170 & 3.043 to 3.294 & 0.915 \\
\hline$B W=P O D L^{\star b}$ & 0.0207 & 3.05 & 0.0172 to 0.0249 & 2.980 to 3.13 & 0.962 \\
\hline$B W=a^{\star} P c L^{b}$ & 0.5018 & 3.18 & 0.4236 to 0.5944 & 3.048 to 3.315 & 0.906 \\
\hline$B W=a^{*} P v L b$ & 0.3730 & 3.03 & 0.3216 to 0.4325 & 2.934 to 3.141 & 0.935 \\
\hline$B W=a^{\star} A n s L^{b}$ & 0.1635 & 2.89 & 0.1348 to 0.1982 & 2.781 to 2.997 & 0.924 \\
\hline$B W=a^{*} \operatorname{PrAnL} b$ & 0.1378 & 2.95 & 0.1136 to 0.1673 & 2.846 to 3.061 & 0.927 \\
\hline$B W=a^{*} P o A n L^{b}$ & 0.0189 & 3.14 & 0.0155 to 0.0230 & 3.061 to 3.232 & 0.958 \\
\hline
\end{tabular}

$n$, sample size; $a$ and $b$ are LWR parameters; $C L$, confidence intervals; $r^{2}$, coefficient of determination. 
Table 3. The estimated parameters of the length-length relationships $(y=a+b \times x)$ Channa orientalis $(n=$ 230) captured from the Gajner Beel, NW Bangladesh

\begin{tabular}{|c|c|c|c|c|c|}
\hline \multirow{2}{*}{ Equation } & \multicolumn{2}{|c|}{ Regression parameters } & \multirow{2}{*}{$95 \% \mathrm{CL}$ of $\mathrm{a}$} & \multirow{2}{*}{$95 \% C L$ of $b$} & \multirow{2}{*}{$r^{2}$} \\
\hline & $a$ & $b$ & & & \\
\hline$T L=a+b \star S L$ & 1.6250 & 1.17 & 1.3952 to 1.8926 & 1.158 to 1.184 & 0.992 \\
\hline$T L=a+b{ }^{\star} \operatorname{PrDL}$ & 1.3432 & 3.61 & 0.8280 to 2.1789 & 3.485 to 3.739 & 0.931 \\
\hline$T L=a+b * P o D L$ & 1.5754 & 1.25 & 1.2198 to 2.0347 & 1.230 to 1.277 & 0.979 \\
\hline$T L=a+b \star P c L$ & 1.2001 & 3.82 & 0.7194 to 2.0020 & 3.822 to 3.681 & 0.925 \\
\hline$T L=a+b \star P v L$ & 1.6968 & 3.17 & 1.1192 to 2.5726 & 3.079 to 3.275 & 0.947 \\
\hline$T L=a+b^{\star} A n s L$ & 2.3663 & 2.16 & 1.5794 to 3.5453 & 2.096 to 2.229 & 0.947 \\
\hline$T L=a+b * \operatorname{PrAnL}$ & 1.8870 & 2.16 & 1.2777 to 2.7868 & 2.096 to 2.222 & 0.952 \\
\hline$T L=a+b * P o A n L$ & 1.1724 & 1.32 & 0.8867 to 1.5501 & 1.329 to 1.356 & 0.976 \\
\hline
\end{tabular}

$n$, sample size; $a$, intercept; $b$, slope; $C L$, confidence intervals; $r^{2}$, coefficient of determination.

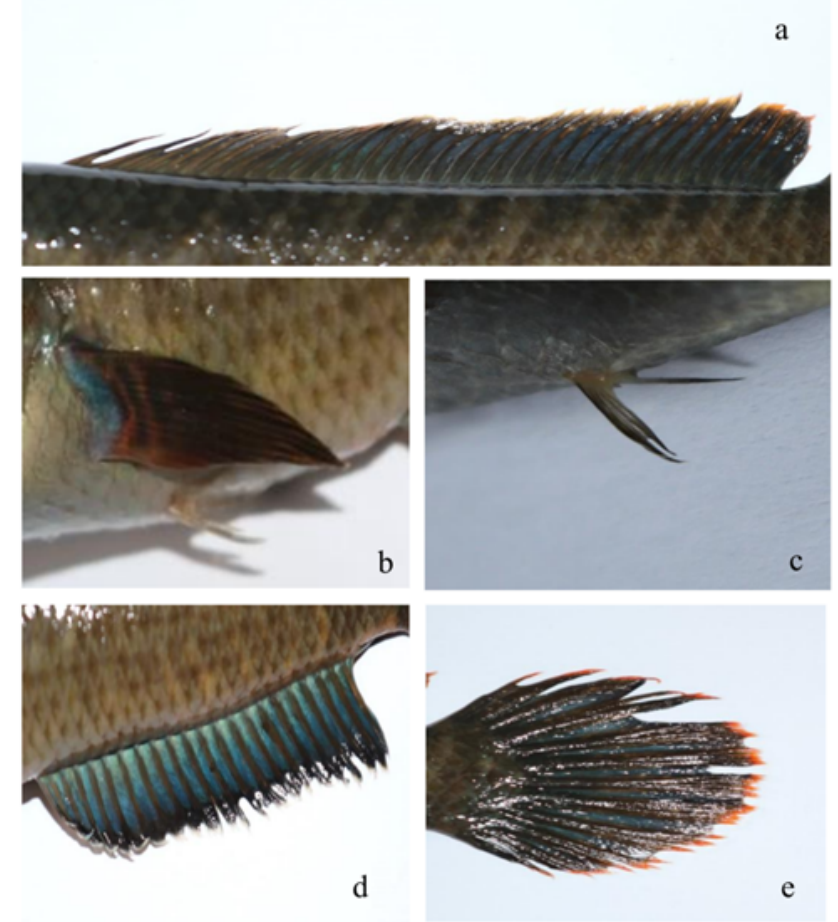

Fig. 3: Showing the meristic characteristics of Channa orientalis from Gajner beel, NW Bangladesh. 


\section{Discussion}

Information on the morphometric and meristic traits are quite insufficient for $C$. orientalis in Gajner Beel, NW Bangladesh though a very few works have been done on morphometric and meristic traits of $C$. orientalis worldwide. So, this is the first complete and informative work on morphometric and meristic characters of $C$. orientalis in the Gajner Beel. During this study, absence of $C$. orientalis smaller than $7.9 \mathrm{~cm}$ TL may be assigned for the selectivity of the fishing gear or fishermen did not go there where fish species were larger sizes, or the species did not go up with larger sizes in the wetland ecosystem. During this study, the maximum length was $18.5 \mathrm{~cm} \mathrm{TL}$, that is quite similar with previous study in Gajner Beel $(18.4 \mathrm{~cm} \mathrm{TL})$ (Hossain et al. 2017a) and also similar with the findings observed in Ravi River, India (19.0 cm TL) (Sharma et al. 2015). Maximum length is beneficial to calculate the growth parameters (i.e., asymptotic length, growth coefficient), thereby essential for resource management for fisheries (Hossain et al. 2017a).

The allometric co-efficient (b) values of LWRs may vary between 2.0 and 4.0 (Carlander 1969) and the allometric co-efficient (b) values of LWRs also ranging from 2.5 to 3.5 are more common (Froese 2006). In our study, the allometric co-efficient, $b$ value was 3.17 which indicated as allometric growth pattern. The $b$ values of LWRs ranging from 2.5 to 3.5 are more general (Islam et al. 2021) and our value is within the range. In general $b$ values close to 3 , indicate that fish grow isometrically and it different from 3.0 indicate allometric growth ( $>3$ positive allometry and $<3$ negative allometry) (Tesch 1971). So, our present study shows $b$ values greater than 3 which indicates positive allometric growth pattern. Some previous research had been reported the $b$ value as 3.17 (Hossain et al. 2017a) and 3.01 at Gajner Beel northwestern Bangladesh and at Ravi River, India respectively (Sharma et al. 2015).

The observed $b$ value will be effective for future research especially in this habitat or other. However, the $b$ values may divers in the same species because of the assemblage of several factors including habitat, variations of growth in different body parts, stage of stomach fullness, sex, seasonal effect, physiology, gonadal maturation, preservation methods and differences in the observed length ranges of the specimens collected which were not accounted during the present study (Tesch 1971, Hossain et al. 2015, Hossain et al. 2017b, Hossain et al. 2018). Besides, all of LLRs were shown highly correlated $(p<0.0001)$. In this study, the observed fin formula was dorsal fin, D. 29-35; pectoral fin, $\mathrm{P}_{1}$. 12-14; pelvic fin, $\mathrm{P}_{2} .5-6$; anal, A. 20-22; and caudal fin, C.12-14 which was similar with the earlier studies (Rahman 1989, Talwar and Jhingran 1991). This study shows that different fins are presented in pictorial format separately which can be very effective for future research in this habitat or other.

\section{Conclusion}

This study highlights the baseline of biological information which should be helpful for the development of management strategies in relation to the fishery. It would also be helpful for the conservation of $C$. orientalis population in Gajner Beel, a wetland ecosystem and the neighboring ecosystems.

\section{Acknowledgements}

The authors would like to express their authentic appreciation to the PIU-BARC, NATP-2, Sub-Project ID: 484 for funding to carry out the Project (Management of indigenous fishes in the Wetland (Gajner Beel, Pabna) Ecosystem and it also a partial work of this CRG (Competitive research grant) Project. 


\section{References}

Bagenal TB and Tesch FW (1978). Age and growth. In methods for assessment of fish production in fresh waters, $3^{\text {rd }}$ ed., edited by TBagenal. IBP Handbook No.3, Blackwell Science Publications, Oxford.

Carlander KD (1969). Handbook of freshwater fishery biology, Vol. 1. The lowa State University Press, Ames, IA: 1-752.

Charjan AP and Kulkarni KM (2014). Morphometric and meristic variations in fins of Channa orientalis (Sch.) from fresh water habitats in Akola district (M.S.) India. International Journal of Biology, 6(1): 152-153.

Dynes P, Magnan L, Bernatchez MA and Rodringue (1999). Genetic and morphological variation between two forms of lacustrine brook charr. Journal of Fish Biology, 154: 955-972.

Froese R (2006). Cube law, condition factor and weight length relationship: History meta-analysis and recommendations. Journal of Applied Ichthyology, 22: 241-253.

Froese R and Pauly D (2019). FishBase, World Wide Web electronic publication. Available at: http://www.fishbase.org.

Hasan MR, Mawa Z, Hassan HU, Rahman MA, Tanjin S, Ahmed Abro N, Gabol K, Bashar MA, Jasmine S, Ohtomi J and Hossain MY (2020). Impact of eco-hydrological factors on growth of the Asian stinging catfish Heteropneustus fosslis (Bloch, 1794) in a Wetland Ecosystem. Egyptian Journal of Aquatic Biology and Fisheries, 24(5): 77-94.

Hossain MY (2010). Morphometric relationships of length-weight and length-length of four Cyprinid small indigenous fish species from the Padma River (NW Bangladesh). Turkish Journal of Fisheries and Aquatic Sciences, 10: 131-134.

Hossain MY, Hossen MA, Khatun D, Nawer F, Parvin MF, Rahman O and Hossain MA (2018). Morphometric and meristic characteristics of Salmostoma bacaila (Hamilton, 1822) (Cyprinidae) from the Ganges River (Northwestern Bangladesh). Jordan Journal of Biological Sciences. 11: 533-536.

Hossain MY, Hossen MA, Ahmed ZF, Hossain MA, Pramanik MNU, Nawer F, Paul AK, Khatun D, Haque N and Islam A (2017a). Length-weight relationship of 12 indigenous fish species in the Gajner Beel floodplain (NW Bangladesh). Journal of Applied Ichthyology, 33: 842-845.

Hossain MY, Hossen MA, Khatun D, Nawer F, Parvin MF, Rahman O and Azad KA (2017b). Morphometric relationships of the Tank goby Glossogobius giuris (Hamilton, 1822) in the Gorai River using multi-linear dimensions. Jordan Journal of Biological Sciences, 10: 57-62.

Hossain MY, Sayed SRM, Rahman MM, Ali MM, Hossen MA, Elgorban AM, Ahmed ZF and Ohtomi J (2015). Lengthweight relationships of nine fish species from the Tetulia River, southern Bangladesh. Journal of Applied Ichthyology, 31: 967- 969.

Hossain MY, Rahman MM, Abdallah EM and Ohtomi J (2013). Biometric relationships of the Pool barb Puntius sophore (Hamilton 1822) (Cyprinidae) from three major rivers of Bangladesh. Sains Malaysiana, 22: 1571-1580.

Hossen MA, Hossain MY, Pramanik MNU, Nawer F, Khatun D, Parvin MF and Rahman MM (2016). Morphological characters of Botia lohachata. Journal of Coastal Life Medicine, 4: 689-692.

IUCN Bangladesh. (2015). Red List of Bangladesh. Volume 5: Freshwater Fishes. IUCN, International Union for Conservation of Nature, Bangladesh Country Office, Dhaka, Bangladesh, pp. 1-360.

IUCN (2019).IUCN Red List of Threatened Species. Version 2019-1. Available at: www.iucnredlist.org

Islam MA, Mawa Z, Hossain MY, Rahman MA, Hasan MR, Khatun D, Chowdhury AA, Rahman O, Tanjin S and Ohtomi J (2020) Morphometric and meristic characteristics of Spotted snakehead Channa punctata (Bloch, 1793) in a wetland ecosystem (NW Bangladesh) using multi-linear dimensions. Indian Journal of Geo-Marine Sciences, 49(8): 1442-1446.

Jayaram KC (1999). The freshwater fishes of the Indian region. Narendra Publishing House, Delhi, pp. 1-551.

King M (2007). Fisheries Biology, Assessment and Management. 2nd ed., Oxford Press, London, pp. 1-382. 
Muchlisin ZA (2013). Morphometric variations of Rasbora group (Pisces: Cyprinidae) in Lake Laut Tawar, Aceh Province, Indonesia, based on truss character Analysis. HAYATI Journal of Biosciences, 20: 138-143.

Nawer F, Hossain MY, Hossen MA, Khatun D, Parvin MF, Ohtomi J and Islam MA (2017). Morphometric relationships of the endangered Ticto barb Pethia ticto (Hamilton, 1822) in the Ganges River (NW Bangladesh) through multi-linear dimensions. Jordan Journal of Biological Sciences, 10: 199-203.

RAHMAN AKA (1989). Freshwater fishes of Bangladesh. Zoological Society of Bangladesh, Department of Zoology, University of Dhaka, Dhaka, pp. 68-69.

Rahman MA, Hasan MR, Hossain MY, Islam MA, Khatun D, Rahman O, Mawa Z, Islam MS, Chowdhury AA, Parvin MF and Khatun $\mathrm{H}$ (2019). Morphometric and meristic characteristics of the Asian stinging catfish Heteropneustes fossilis (Bloch, 1794): A key for identification. Jordan Journal of Biological Science, 12: 467-70.

Rainboth WJ (1996). Fishes of the Cambodian Mekong. FAO species identification field guide for fishery purposes. FAO, Rome, pp. 1-265.

Sharma NK, Mir JI, Singh R, Akhtar MS and Pandey NN (2015). Length-weight relationships for eight fish species from the Ravi River, northwestern India. Journal of Applied Ichthyology, 31: 1146-1147.

Talwar PK and Jhingran AG (1991). Inland Fishes of India and Adjacent Countries. Balkema AA (ed), Rotterdam, Netherlands.

Tesch FW (1971). Age and growth. In: Ricker WE (Eds.). Methods for assessment of fish production in fresh waters. Blackwell Scientific Publications, Oxford, pp. 99-113.

(Manuscript received on 27 January 2021; revised on 27 May 2021) 